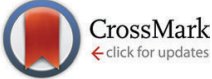

Cite this: Phys. Chem. Chem. Phys., 2015, 17, 5403

Received 1st December 2014, Accepted 13th January 2015

DOI: $10.1039 / c 4 c p 05587 j$

www.rsc.org/pccp

\title{
Temperature-induced amorphisation of hexagonal ice
}

\author{
Philip H. Handle and Thomas Loerting*
}

\begin{abstract}
We systematically studied the competition between polymorphic transformations and amorphisation of hexagonal ice on isobaric heating from $77 \mathrm{~K}$ to $155-170 \mathrm{~K}$ at pressures between 0.50 and $1.00 \mathrm{GPa}$. This competition is analysed here systematically by in situ dilatometry and ex situ X-ray diffraction and calorimetry. Volume vs. temperature curves were analysed using a novel fitting approach in order to understand the underlying mechanism. Hexagonal ice undergoes solid-state-transformation to ice IX/III at 0.50 and $0.60 \mathrm{GPa}$ and to a mixture of ices IX/III and IV at 0.70 and $0.80 \mathrm{GPa}$. Possibly a tiny fraction of amorphous intermediate is transiently formed in this pressure range. At $0.85 \mathrm{GPa}$ the amorphisation process becomes competitive, and leads to very high-density amorphous ice (VHDA) as by-product. At 0.90 and $0.95 \mathrm{GPa}$ VHDA is the main product and at 1.00 GPa only VHDA is found. This represents the first observation of temperature-induced amorphisation (TIA) for hexagonal ice using diffraction methods. Our analysis suggests TIA to be a first-order phase transition which, by contrast to pressure-induced amorphisation (PIA), does not involve a precursor process. We suggest interpreting TIA as thermodynamic melting of ice followed by immediate vitrification rather than as mechanical collapse of hexagonal ice. The activation energies for amorphisation and polymorphic transformation are equal at $\sim 0.75 \mathrm{GPa}$. At $1.00 \mathrm{GPa}$ the activation energy for amorphisation of hexagonal ice is lower by about $6 \mathrm{~kJ} \mathrm{~mol}^{-1}$ than the activation energy for polymorphic transitions.
\end{abstract}

\section{Introduction}

Amorphisation of crystalline material at high-pressure conditions is a rather unusual phenomenon. Most materials actually experience the reverse transformation from amorphous to crystalline at high-pressure conditions. Pressure-induced amorphisation (PIA) was so far only demonstrated for just a few materials. ${ }^{1}$ These materials, e.g., silica, ${ }^{2}$ zeolites, ${ }^{3} \mathrm{GeSe}_{2},{ }^{4}$ silicon $^{5}$ or water, ${ }^{6}$ have in common that they show anomalous properties such as the density maximum in the liquid or the negatively sloped melting line. The discovery of high-density amorphous ice (HDA) in $1984^{6}$ marked the first example of PIA. Mishima described this process as thermodynamic melting of hexagonal ice, ${ }^{6}$ whereas later calculations suggest to interpret the process as crystalbreakdown due to mechanical instability. ${ }^{7}$ In this latter view the product is not liquid-like, but shows crystal-like behaviour. ${ }^{8}$ In fact, there might be a crossover from a thermodynamic melting at higher temperatures to mechanical melting at lower temperatures. ${ }^{8,9}$ Extrapolations of inelastic neutron scattering experiments are consistent with the idea of mechanical melting, ${ }^{10}$ and more recent studies point towards a change in mechanism between 80 and $100 \mathrm{~K} \cdot{ }^{11,12}$ Lately, rapid decompression experiments

Institute of Physical Chemistry, University of Innsbruck, Innrain 80-82, A-6020 Innsbruck, Austria.E-mail: thomas.loerting@uibk.ac.at showed PIA from ice VII to HDA. ${ }^{13}$ In addition to PIA the anomalous materials mentioned above might also experience temperature-induced amorphisation (TIA) upon heating the material at high-pressure conditions. There are only a few scattered studied about this possibility. ${ }^{14-18}$ Interestingly, not all materials showing PIA also show TIA. In case of the zeolitic material ZIF-8 PIA was observed ${ }^{19}$ whereas TIA could not be observed. ${ }^{20}$ A MD Study on ZIF-8 by Ortiz et al. suggested that shear-mode softening is required for amorphisation to occur, which in ZIF-8 is only experienced upon pressurizing, but not upon heating the material isobarically. ${ }^{3}$ In case of ice temperature-induced routes to amorphous ices have so far been barely investigated. Amorphisation was reported for some high-pressure ice forms upon heating at ambient pressure conditions. It was found that ices VII ${ }^{21} \mathrm{VIIII}^{22}$ and $\mathrm{XII}^{23}$ experience a temperature-induced transition to low-density amorphous ice (LDA) at ambient pressure. Also a pressure-induced path to LDA was found on decompression of ice $\mathrm{VII}^{\prime} .{ }^{24}$ In these cases the amorphisation is a transient phenomenon, which can only be observed in a rather narrow temperature window and accompanies the polymorphic crystal-crystal transition ultimately resulting in cubic ice. In fact, it is questionable ${ }^{21}$ whether the amorphous form produced transiently is closer to HDA or LDA. ${ }^{25}$ In our opinion it is also possible that the transient amorphous ices produced on the way from the high-pressure ice forms to cubic 
ice are in fact materials, in which the oxygen atoms have become mobile prior to the transition and have moved to off-lattice positions in the course of the high-density crystal to low-density crystal transition. To our knowledge the only TIA from hexagonal ice to HDA was reported by Gromnitskaya et al., who have claimed that amorphisation of hexagonal ice can be achieved under isobaric conditions. ${ }^{26}$ In fact, they claim TIA only for a single instance, namely for heating of hexagonal ice at $0.77 \mathrm{GPa}$. This study was done using the propagation of ultrasound through the sample as a probe, so the crystalline or amorphous nature of the sample was inferred indirectly. The process of TIA of hexagonal ice at isobaric high-pressure conditions as suggested by Gromnitskaya et al. results in HDA, just like the process of PIA of hexagonal ice at isothermal conditions. From their analysis, they concluded that elastic softening precedes solid-state amorphisation. More precisely, the softening of the transverse acoustic phonons at the Brillouin zone boundary is followed by instability. ${ }^{26}$ At highpressure conditions hexagonal ice may either transform to highpressure ice polymorphs or amorphise. Here, we investigate the competition between the two high-pressure mechanisms by investigating temperature-induced transformations of hexagonal ice at $0.50 \leq p \leq 1.00$ GPa using high-precision high-pressure dilatometry. A systematic analysis of this competition is lacking so far and, thus, is the focus in this work. Rather than establishing the nature of the phases from an ultrasonic study as done by Gromnitskaya et $a .^{26}$ we here analyze the microscopic structure of the sample directly by means of powder X-ray diffraction and the thermal properties by differential scanning calorimetry. The mechanism of the high-pressure transformations is analysed by a novel method of fitting the volume $v s$. temperature curves.

\section{Methods}

$250 \mu \mathrm{l}$ of ultrapure water were frozen to hexagonal ice at $77 \mathrm{~K}$ in a preformed indium container made from about $400 \mathrm{mg}$ indium foil of thickness $0.1 \mathrm{~mm}$. Then the sample container was pushed into a steel cylinder of bore diameter $8 \mathrm{~mm}$, compressed at $77 \mathrm{~K}$ to $1.0 \mathrm{GPa}$ and subsequently decompressed to $0.50 \leq p \leq$ $1.00 \mathrm{GPa}$. Compression and decompression rates were either 0.20 or $0.14 \mathrm{GPa} \mathrm{min}^{-1}$. After this procedure the sample can be described as a compact, air-free pressurised cylinder of polycrystalline hexagonal ice without microcracks or micropores. Temperature-induced phase transformations were followed thereafter by recording piston displacement (volume) changes on isobaric heating at $3 \mathrm{~K} \mathrm{~min}^{-1}$ to $\sim 155 \mathrm{~K}(0.70 \leq p \leq$ $1.00 \mathrm{GPa}), \sim 165 \mathrm{~K}(0.60 \mathrm{GPa})$ or $\sim 170 \mathrm{~K}(0.50 \mathrm{GPa})$. The samples were then quenched to $77 \mathrm{~K}$ by immersing the setup in liquid nitrogen and recovered to ambient pressure. The quenchrecovered materials were finally characterised $e x$ situ by powder X-ray diffraction (XRD) and differential scanning calorimetry (DSC). To that end, the samples were cold-loaded under liquid nitrogen to the cold ( $77 \mathrm{~K}$ ) sample holder in the XRD-chamber and to DSC-crucibles placed into the DSC-instrument, which was pre-thermostated at $93 \mathrm{~K}$. Diffractograms were recorded at $77 \mathrm{~K}$ in the range $10<2 \theta<54^{\circ}$ at $\sim 80 \mathrm{~K}$ and at approximately
$10^{-1}$ mbar using $\mathrm{Cu}-\mathrm{K}_{\alpha}$ radiation $(1.541 \AA$ ), following the standard procedure employed in many studies in the past in our group (for recent reviews see ref. 27-29). The phase compositions of crystalline samples containing more than one polymorph were determined using the program PowderCell (version 2.4, BAM, Bundesanstalt für Materialforschung und -prüfung, Berlin, Germany). The appearance of traces of hexagonal ice in some diffractograms is attributed to ice condensation from humid air during sample transfer into the XRD chamber. Therefore, hexagonal ice features are neglected for interpretation. The relevant structural data were taken from ref. 30, 31 (ice IV) and 32 (ice IX/III). Thermograms were recorded by performing two scans with a heating rate of $10 \mathrm{~K} \mathrm{~min}^{-1}$ : the first scan from 93 to $233 \mathrm{~K}$ to record the latent heat of phase transformation(s) and a second scan from 93 to $293 \mathrm{~K}$ which serves both as baseline and to calculate the sample mass from the melting endotherm of hexagonal ice. Volume curves were calculated from dilatometry data and corrected for the apparatus behaviour by subtracting a blind experiment ${ }^{33}$ and using the density of ice at $77 \mathrm{~K}$ and 1 bar $\left(0.932 \mathrm{~g} \mathrm{~cm}^{-3} ; 19.3 \mathrm{~cm}^{3} \mathrm{~mol}^{-1}\right) .{ }^{34}$ Furthermore the pressure dependence of the molar volume of hexagonal ice was determined by a polynomic fit of fifth order to compression data of hexagonal ice from a measurement up to $1 \mathrm{GPa}$ at $77 \mathrm{~K}$. Molar volumes calculated from this polynomial serve as initial values for the isobaric heating curves.

For an in-depth analysis the volume curves were fitted by a custom function. This function has been obtained by an ansatz analogous to the one described by Moynihan: ${ }^{35}$

$$
\frac{\mathrm{d}\left(V_{\mathrm{m}}-V_{\mathrm{m}, \mathrm{e}}\right)}{\mathrm{d} t}=-k\left(V_{\mathrm{m}}-V_{\mathrm{m}, \mathrm{e}}\right)
$$

where $V_{\mathrm{m}}$ is the molar volume at time $t, V_{\mathrm{m}, \mathrm{e}}$ the molar volume in equilibrium and $k$ is the rate constant. In the experiments shown here temperature is varying and, therefore, also $k$. The temperature dependence of $k$ is given by ${ }^{36,37}$

$$
E_{\mathrm{A}}=R T^{2}\left(\frac{\partial \ln k}{\partial T}\right)_{p}
$$

where $R$ is the ideal gas constant and $E_{\mathrm{A}}$ the activation energy. Integration and substitution of $k$ by the inverse of the relaxation time $\tau_{R}^{35}$ in eqn (2) leads to

$$
\tau_{R}=\tau_{R, \infty} \cdot \mathrm{e}^{\frac{E_{\mathrm{A}}}{R T}}
$$

where $\tau_{R, \infty}$ is the relaxation time at infinite temperature, which results from the integration constant in above integration and yields the Arrhenius equation. Combining eqn (1) and (3) yields

$$
\frac{\mathrm{d}\left(V_{\mathrm{m}}-V_{\mathrm{m}, \mathrm{e}}\right)}{\mathrm{d} t}=-\frac{1}{\tau_{R, \infty}} \cdot \mathrm{e}^{-\frac{E_{\mathrm{A}}}{R T}}\left(V_{\mathrm{m}}-V_{\mathrm{m}, \mathrm{e}}\right)
$$

Separation of variables, substitution of the time dependent temperature $T$ by $\left(T_{0}+q t\right)$ where $T_{0}$ is the starting temperature and $q$ the heating rate and formulation of the integral from the starting volume $V_{\mathrm{m}, 0}$ at time 0 to the volume at $t$ leads to

$$
\int_{V_{\mathrm{m}, 0}}^{V(t)} \frac{\mathrm{d}\left(V_{\mathrm{m}}-V_{\mathrm{m}, \mathrm{e}}\right)}{V_{\mathrm{m}}-V_{\mathrm{m}, \mathrm{e}}}=-\frac{1}{\tau_{R, \infty}} \int_{0}^{t} \mathrm{e}^{-\frac{E_{\mathrm{A}}}{R\left(T_{0}+q t\right)}} \mathrm{d} t
$$


The left side of this equation is easy to solve, whereas the right side can only be solved numerically, by means of the exponential integral $\mathrm{Ei}(x)$, which is defined by

$$
\operatorname{Ei}(x)=\int_{-\infty}^{x} \frac{\mathrm{e}^{\xi}}{\xi} \mathrm{d} \xi
$$

Therefore the solution of the above differential equation is

$$
\ln \frac{V_{\mathrm{m}}(t)-V_{\mathrm{m}, \mathrm{e}}}{V_{\mathrm{m}, 0}-V_{\mathrm{m}, \mathrm{e}}}=-\frac{\Xi(t)}{R q \tau_{R, \infty}}
$$

where the function $\Xi(t)$ is

$$
\begin{aligned}
\Xi(t)= & E_{\mathrm{A}}\left[\operatorname{Ei}\left(-\frac{E_{\mathrm{A}}}{R T(t)}\right)-\operatorname{Ei}\left(-\frac{E_{\mathrm{A}}}{R T_{0}}\right)\right] \\
& +R\left[T(t) \cdot \mathrm{e}^{-\frac{E_{\mathrm{A}}}{R T(t)}}-T_{0} \cdot \mathrm{e}^{-\frac{E_{\mathrm{A}}}{R T_{0}}}\right]
\end{aligned}
$$

with $T(t)=\left(T_{0}+q t\right)$. Rearrangement and use of $\Delta_{\mathrm{e}} V_{\mathrm{m}}=V_{\mathrm{m}, \mathrm{e}}-V_{\mathrm{m}, 0}$ and $\Delta V_{\mathrm{m}}(t)=V_{\mathrm{m}}(t)-V_{\mathrm{m}, 0}$ leads to

$$
\Delta V_{\mathrm{m}}(t)=\Delta_{\mathrm{e}} V_{\mathrm{m}}\left(1-\mathrm{e}^{-\frac{\Xi(t)}{R q \tau} R, \infty}\right)
$$

Finally two empirical changes were made. First a linear term $\propto_{p}^{V_{\mathrm{m}}}$ $\left(T(t)-T_{0}\right)$ was added to account for the fast relaxation ( $c f$. ref. 35) and second an exponent $\beta_{p}^{V_{\mathrm{m}}}$ similar to the KWW function ( $c f$. e.g. ref. 35 and 38) was added which leads to the fit function used here

$$
\Delta V_{\mathrm{m}}(t)=\Delta_{\mathrm{e}} V_{\mathrm{m}}\left(1-\mathrm{e}^{-\left(\frac{\Xi(t)}{R q \tau_{R, \infty}}\right) \beta_{p}^{V_{\mathrm{m}}}}\right)+\propto_{p}^{V_{\mathrm{m}}}\left(T(t)-T_{0}\right)
$$

The volume curves were fitted as functions of temperature with the Curve Fitting Toolbox of MATLAB R2013a.

\section{Results}

Exemplary volume curves of the isobaric heating step are shown in Fig. 1. All curves shown in Fig. 1 exhibit a densification step, which shifts to lower temperature with increasing pressure. All steps mark solid-solid transformations analysed in more detail below. The reproducibility for these curves and the location of the steps is excellent in general. However, in case of 0.90 and 0.95 GPa we found two distinct set of curves, in which the location of the step is shifted by about $10 \mathrm{~K}$. It seems there are two possible solid-solid transitions, one resulting in a step at low temperature (solid lines in Fig. 1), and the other resulting in a step at high temperature (dashed lines in Fig. 1). We did not find a way of controlling this competition between two phase transformations at 0.90 and 0.95 GPa.

Representative diffractograms are shown in Fig. 2, and the phase-compositions of the ice samples are summarised in Table 1 . Up to $0.85 \mathrm{GPa}$ the heating leads to predominantly crystalline material, which is ice IX/III or IV. This is in contrast to the result presented by Gromnitskaya et al., who claim temperature-induced amorphisation at $0.77 \mathrm{GPa}$ and 130$140 \mathrm{~K}^{26}$ Samples heated at higher pressures show amorphous X-ray patterns with only minor crystalline amounts. At 0.50 and $0.60 \mathrm{GPa}$ only ice IX/III occurs, at $0.70-0.85 \mathrm{GPa}$ both ice IX/III and

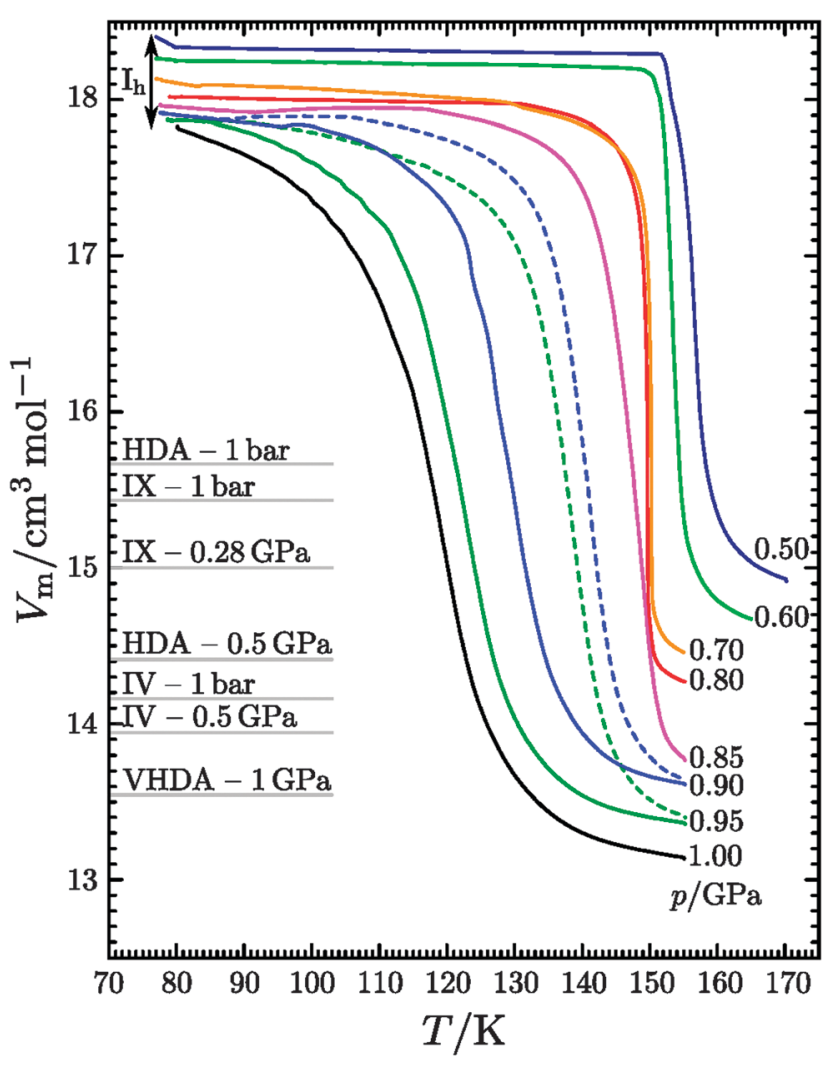

Fig. 1 Molar volume $V_{m}$ at isobaric heating of hexagonal ice at elevated pressures. The initial values were calculated by a polynomic fit of a compression curve of hexagonal ice (cf. text). Cooling curves are omitted for clarity. Also the molar volumes of HDA and VHDA at 1 bar $^{48}$ as well as at higher pressures (from Fig. 5 in ref. 27), ice IV at 1 bar ${ }^{31}$ as well as at higher pressures ${ }^{41,63,64}$ and ice IX ${ }^{65}$ are shown. Thermal expansion was neglected due to the marginal influence on the scale shown.

ice IV appear, where the ice IV fraction increases with pressure. Please note that ices III and IX cannot be distinguished based on powder X-ray diffraction measurements, because they share the same network of O-atoms and only differ in terms of protonordering. Ice IV, just like HDA, transforms to ice VI at highertemperatures. Since Gromnitskaya et al. did not consider ice IV at all in their study, we think that it is possible that the ultrasonic properties reported in their Fig. 3(b) do not indicate the TIA process followed by transformation to ice VI, ice $\mathrm{I}_{\mathrm{h}} \rightarrow \mathrm{HDA} \rightarrow$ ice VI, but rather the polymorphic transition sequence ice $\mathrm{I}_{\mathrm{h}} \rightarrow$ ice IV/III/IX $\rightarrow$ ice VI. As detailed below at most some transient traces of HDA might appear, which immediately crystallise in the temperature/ pressure region investigated by Gromnitskaya et al. At 0.90$1.00 \mathrm{GPa}$, only amorphous ice or amorphous ice with traces of ice IV occurs. Ice IV is known to crystallise from amorphous ice at high-pressure conditions, ${ }^{39-41}$ but has never been observed to crystallise from hexagonal ice or any other ice polymorph. By contrast, ice IX/III may crystallise from hexagonal ice or from ice V. ${ }^{42-46}$ The amorphous halo peak, also called first sharp diffraction peak by some,${ }^{47}$ is found at $2 \theta=32.5^{\circ}$ (see dotted grey line in Fig. 2), which corresponds to the position found in very high-density amorphous ice (VHDA). ${ }^{48}$ That is, amorphous ice produced by isobaric heating experiments at $>0.85$ GPa corresponds to VHDA. 


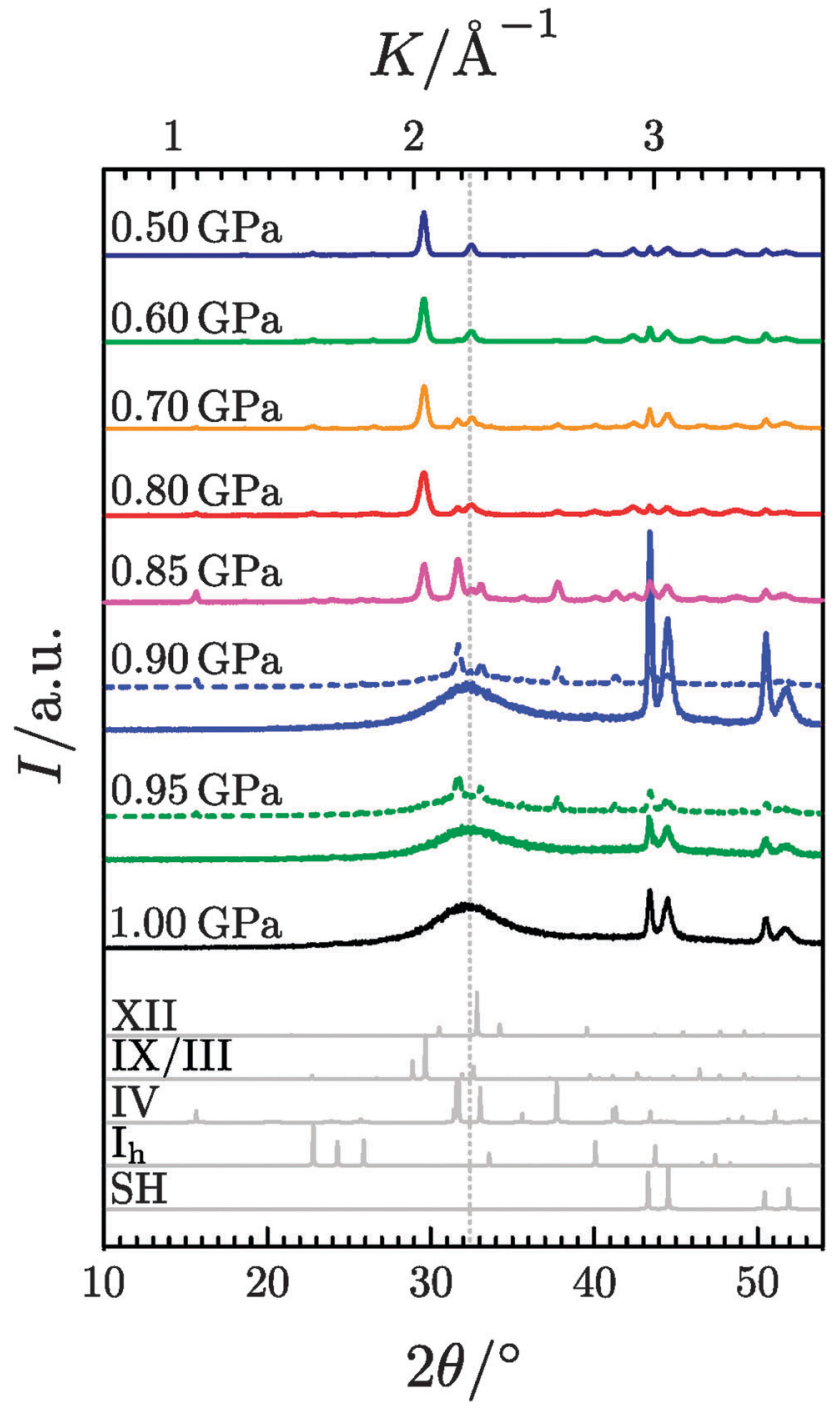

Fig. 2 XRD measurements at ambient pressure and $77 \mathrm{~K}$ of samples recovered after isobaric heating of hexagonal ice at elevated pressures. The diffractograms were recorded at ambient pressure from samples quench-recovered after the isobaric heating shown in Fig. 1 (corresponding XRD measurements and volume curves in Fig. 1 have the same colour). The grey curves in the lower part show calculated diffractograms for ices $I_{h}, I V, I X / I I I$ and XII as well as for the sample holder $(\mathrm{SH})$ made from nickel-plated copper. The dotted line at $2 \theta=32.4^{\circ}$ indicates the halomaximum of VHDA produced by heating $\mathrm{U}-\mathrm{HDA}$ at $1.1 \mathrm{GPa}$ to $160 \mathrm{~K}$ with $3 \mathrm{~K} \mathrm{~min}^{-1}$ and subsequent quench-recovery to $1 \mathrm{bar}^{48}$

The samples heated at 0.90 and $0.95 \mathrm{GPa}$, which exhibit the low transition temperature (solid line in Fig. 1) show pure VHDA patterns, whereas the samples which exhibit the high transition temperatures (dashed line in Fig. 1) show traces of ices IV and IX/III in addition to VHDA.

The same conclusions can be drawn from the representative thermograms shown in Fig. 3. Only one exotherm is found for samples prepared at $<0.85 \mathrm{GPa}$, whereas two or three exotherms are found for samples prepared at $\geq 0.85 \mathrm{GPa}$. In the former case the exotherm is observed between 150 and $160 \mathrm{~K}$. While the exotherm is symmetric at 0.50 and $0.60 \mathrm{GPa}$ it is asymmetric at 0.70 and $0.80 \mathrm{GPa}$. (cf. Fig. 3(a)). This
Table 1 Summary of the phase-composition deduced from XRD measurements after isobaric heating of hexagonal ice at the respective pressures. $2 \theta_{\max }$ stands for the maximum of the amorphous halo peak, Compos. for crystalline composition and $X_{\mathrm{A}}: X_{\mathrm{B}}$ for the relative proportion of different crystalline polymorphs in mainly crystalline samples. Each line represents analysis of an individual diffractogram

\begin{tabular}{llllll}
\hline$p / \mathrm{GPa}$ & Compos. & $X_{\mathrm{A}}: X_{\mathrm{B}}(\%)$ & $p / \mathrm{GPa}$ & $2 \theta_{\mathrm{max}} /{ }^{\circ}$ & By-prod. \\
\hline 0.50 & IX/III & 100 & 0.90 & 31.9 & - \\
& IX/III & 100 & & 32.2 & - \\
0.60 & & & & & \\
& IX/III & 100 & & 32.3 & - \\
& IX/III & 100 & & 32.2 & IV, IX/III \\
0.70 & & & & \\
& IV, IX/III & $12: 88$ & & 32.2 & IV, IX/III \\
& IV, IX/III & $6: 94$ & 0.95 & 31.7 & IV \\
0.80 & & & & & \\
& IV, IX/III & $32: 68$ & & 31.7 & IV \\
& IV, IX/III & $31: 69$ & & 32.4 & $\mathrm{I}_{\mathrm{h}}$ \\
& IV, IX/III & $23: 77$ & & 32.1 & IV \\
& IV, IX/III & $31: 69$ & & 32.1 & IV \\
& IV, IX/III & $27: 73$ & & 32.2 & $\mathrm{I}_{\mathrm{h}}$ \\
& IV, IX/III & $12: 88$ & & 32.2 & $\mathrm{I}_{\mathrm{h}}$ \\
& & & & & \\
0.85 & IV, IX/III & $57: 43$ & & 32.5 & - \\
& IV, IX/III & $64: 36$ & & 32.2 & $\mathrm{I}_{\mathrm{h}}$ \\
& IV, IX/III & $66: 34$ & 1.00 & 32.2 & - \\
& IV, IX/III & $63: 37$ & & 32.2 & $\mathrm{I}_{\mathrm{h}}$ \\
& IV, IX/III & $57: 43$ & & 32.3 & $\mathrm{I}_{\mathrm{h}}$ \\
& IV, IX/III & $56: 44$ & & 32.2 & $\mathrm{I}_{\mathrm{h}}$ \\
& & & & 32.3 & $\mathrm{I}_{\mathrm{h}}$
\end{tabular}

exothermic event is attributed to the transformation from ice IV and/or ice IX/III to cubic ice judging from the phasecomposition (Table 1) deduced from the XRD measurements (Fig. 2). A symmetric peak with onset temperature $156 \pm 1 \mathrm{~K}$ results if single phase ice IX/III converts to cubic ice. The latent heat associated with the IX/III $\rightarrow \mathrm{I}_{\mathrm{c}}$ transition as calculated from the peak area amounts to $-269 \pm 36 \mathrm{~J} \mathrm{~mol}^{-1}$. This compares with earlier determinations of $-300 \mathrm{~J} \mathrm{~mol}^{-1}$ by Bertie and Whalley ${ }^{49}$ and of $-340 \mathrm{~J} \mathrm{~mol}^{-1}$ deduced by Handa et al. ${ }^{50}$ The additional presence of ice IV results in the asymmetry of the exotherm, more precisely in the low-temperature shoulder, and a lower onset temperature of $154 \pm 1 \mathrm{~K}$. The asymmetry is more pronounced for the case of $0.80 \mathrm{GPa}$ than for the case of $0.70 \mathrm{GPa}$, thereby qualitatively corroborating the analysis of phase-composition of $30 \pm 5 \%$ ice IV at $0.80 \mathrm{GPa}$ and $10 \pm 5 \%$ ice IV at $0.70 \mathrm{GPa}(c f$. Table 1). The phase composition estimated from the area of the exotherm indicating transformation to cubic ice is $28 \pm 4 \%$ ice IV and $72 \pm 4 \%$ ice IX/III for $0.70 \mathrm{GPa}$ and $34 \pm 21 \%$ ice IV and $66 \pm 21 \%$ ice IX/III for $0.80 \mathrm{GPa}$ using $-269 \pm 36 \mathrm{~J} \mathrm{~mol}^{-1}$ for pure ice IX/III and $-938 \pm 14 \mathrm{~J} \mathrm{~mol}^{-1}$ for pure ice IV. ${ }^{51}$ For the IV $\rightarrow I_{c}$ transition an onset temperature of about $149 \mathrm{~K}$ was found for a $5 \mathrm{~K} \mathrm{~min}^{-1}$ heating rate and $156 \mathrm{~K}$ for $30 \mathrm{~K} \mathrm{~min}^{-1}$ heating rate, ${ }^{51}$ which compares with $154 \pm 1 \mathrm{~K}$ at $10 \mathrm{~K} \mathrm{~min}^{-1}$ found in this work. For the IX $\rightarrow \mathrm{I}_{\mathrm{c}}$ transition an onset temperature of $\sim 143 \mathrm{~K} \dagger$ for a $10 \mathrm{~K} \mathrm{~h}^{-1}$ heating rate ${ }^{50}$ and $\sim 150 \mathrm{~K}$ for the III $\rightarrow \mathrm{I}_{\mathrm{c}}$ transition when heated with $1.1 \mathrm{~K} \mathrm{~min}^{-1}$ (ref. 49) were found, which compares to $156 \pm 1 \mathrm{~K}$ at $10 \mathrm{~K} \mathrm{~min}^{-1}$

$\dagger$ This value represents the mean value of all data in ref. 50 Y. P. Handa, D. D. Klug and E. Whalley, Can. J. Chem., 1988, 66, 919-924. 
$T / \mathrm{K}$

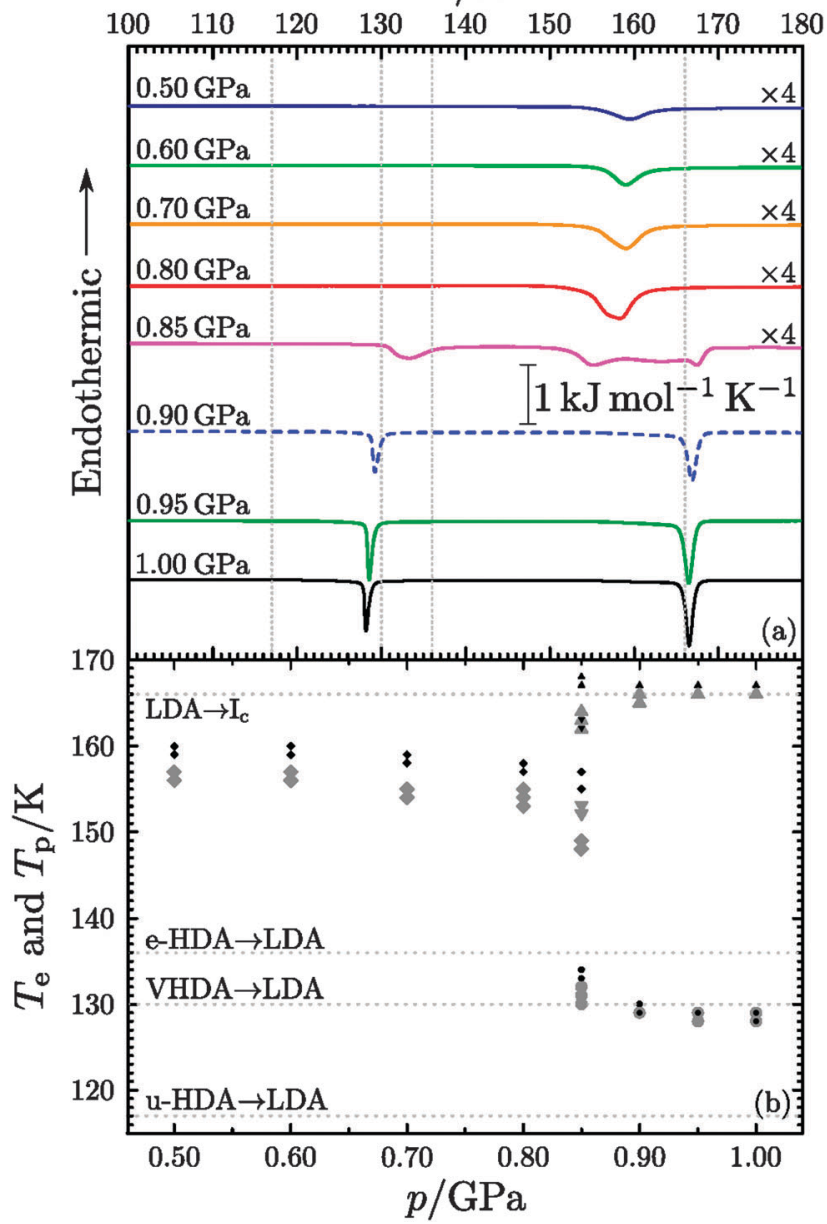

Fig. 3 (a) Exemplary DSC curves of samples recovered after isobaric heating of hexagonal ice at elevated pressures. The calorigrams were recorded at ambient pressure from samples quench-recovered after the isobaric heating shown in Fig. 1 (corresponding DSC measurements and volume curves in Fig. 1 have the same colour). The top five measurements are magnified by a factor of 4 , to achieve comparable signal heights. The dotted lines at 117, 130 and $136 \mathrm{~K}$ mark the onset temperatures of the u-HDA, VHDA and e-HDA $\rightarrow$ LDA transitions, respectively. The u-HDA sample was produced by PIA at $77 \mathrm{~K}$ and the VHDA sample as explained in Fig. 2. For e-HDA VHDA was decompressed at $140 \mathrm{~K}$ to $0.1 \mathrm{GPa}$ and then quench-recovered. Finally the dotted line at $166 \mathrm{~K}$ marks the onset temperature of the LDA $\rightarrow I_{C}$ transition. (b) Large grey symbols mark onset temperatures $T_{\mathrm{e}}$ and black ones peak temperatures $T_{\mathrm{p}}$. The diamonds indicate the polymorphic transition ice IX/III $\rightarrow$ ice $I_{c}(0.5$ \& $0.6 \mathrm{GPa})$ and IX/III \& IV $\rightarrow$ ice $I_{c}(0.7 \& 0.8 \mathrm{GPa})$, the circles the polyamorphic transition VHDA $\rightarrow$ LDA $(0.85-1.00 \mathrm{GPa})$ and the triangles crystallisation of LDA (0.85-1.00 GPa). LDA crystallisation seems to be composed of two types of kinetics as also noted earlier in literature. ${ }^{54}$ Downward triangles indicate the first (low temperature) kinetics and upward triangles the second (high temperature) kinetics. The dotted lines again represent the onset temperatures of the $\mathrm{u}-\mathrm{HDA}, \mathrm{VHDA}$ and e-HDA $\rightarrow$ LDA transition, respectively as well as the onset temperature of the LDA $\rightarrow I_{c}$ transition.

found in this work. That is, the onset temperatures found in this work at $10 \mathrm{~K} \mathrm{~min}^{-1}$ heating rate are where they would be expected from the trends with changing heating rates seen in earlier work. Therefore, the transition temperatures for samples heated at 0.50 and $0.60 \mathrm{GPa}$ are attributed only to ice IX/III ( $c f$. also Table 1).
The DSC scans of samples heated above $0.85 \mathrm{GPa}$ in contrast show two exotherms as expected for amorphous ices of high density. First, the exothermic polyamorphic transition to lowdensity amorphous ice (LDA) takes place with an onset at $129 \pm 1 \mathrm{~K}$, which in turn exothermically crystallises to cubic ice with an onset at $166 \pm 0.5 \mathrm{~K}$. The comparison with the known onset temperatures of u-HDA, e-HDA and VHDA in Fig. 3(b) shows a match with that of VHDA, which again is consistent with the XRD results. The latent heats for the (pure) VHDA $\rightarrow$ LDA and LDA $\rightarrow \mathrm{I}_{\mathrm{c}}$ transformations are found to be $-685 \pm 77 \mathrm{~J} \mathrm{~mol}^{-1}$ and $-1333 \pm 114 \mathrm{~J} \mathrm{~mol}^{-1}$, respectively. This compares to $-640 \pm 10 \mathrm{~J} \mathrm{~mol}^{-1}$ (ref. 52) and the average value $-1314 \pm 93 \mathrm{~J} \mathrm{~mol}^{-1}$ from various literature sources ${ }^{52-57}$ and independent measurements done in this work, respectively. While the diffractograms show the presence of traces of crystalline material for the samples showing the low transition temperature at 0.90 and $0.95 \mathrm{GPa}$, the DSC scans do not reveal the presence of crystallinity. That is, XRD is much more sensitive for the detection of crystalline material than DSC, whereas DSC is much more sensitive for the detection of amorphous material. Additionally only small parts of the samples were used for the DSC scans, i.e., in case the sample was heterogeneous, grains which do not reflect the overall sample composition were possibly picked.

The sample heated at 0.85 GPa finally shows a DSC trace which contains all three exotherms including both the signatures of the polyamorphic and polymorphic transitions of ices IV and IX/III. The latent heats of transformation of $-175 \pm 68 \mathrm{~J} \mathrm{~mol}^{-1}$ $(\mathrm{VHDA} \rightarrow \mathrm{LDA})$ and $-593 \pm 179 \mathrm{~J} \mathrm{~mol}^{-1}\left(\mathrm{LDA} \rightarrow \mathrm{I}_{\mathrm{c}}\right)$ indicate that about $45 \pm 14 \%$ of the material are amorphous at $0.85 \mathrm{GPa}$, even though the diffractogram (Fig. 2, $0.85 \mathrm{GPa}$ ) is dominated by sharp Bragg reflections. The latent heat for the second exotherm to ice $I_{c}$ is found to be $-442 \pm 123 \mathrm{~J} \mathrm{~mol}^{-1}$, which indicates that the crystalline fraction is indeed composed of a mixture of ice IV and ice IX/III. Therefore, 0.85 GPa delineates temperature-induced polymorphic transitions at the low-pressure side from temperatureinduced amorphisation at the high-pressure side.

The results obtained from the DSC and XRD analysis are summarised in Fig. 4. Isobaric heating of hexagonal ice at 0.50 and $0.60 \mathrm{GPa}$ leads to ice IX/III. An intermediate amorphous state can be excluded, because ice $\mathrm{V}$ would be expected if HDA crystallised. ${ }^{58}$ At 0.70 and $0.80 \mathrm{GPa}$ a crystalline mixture of ice IX/III and ice IV results, where ice IV was either formed from a small fraction of intermediately formed HDA or crystallised from hexagonal ice. The isobaric crystallisation of HDA at different heating rates and $0.71 \mathrm{GPa}$ and $0.81 \mathrm{GPa}$ was studied before. $^{39,58}$ In these studies the onset for crystallisation to ice IV was determined to be $\sim 145 \mathrm{~K}$ for slow heating rates of $0.5 \mathrm{~K} \mathrm{~min}^{-1}$. Judging from Fig. 1 the onset of VHDA formation is $\sim 111 \mathrm{~K}$ at $1.0 \mathrm{GPa}$ and $\sim 122 \mathrm{~K}$ at $0.9 \mathrm{GPa}$. It thus seems plausible that VHDA slowly forms at $<145 \mathrm{~K}$ at 0.70 and $0.80 \mathrm{GPa}$. Once formed it then slowly crystallises to ice IV at $>145 \mathrm{~K}$. This slow process of VHDA formation and crystallisation is then immediately truncated once the sharp transition from the remainder of hexagonal ice to ice IX/III kicks in at $\sim 149 \mathrm{~K}$. Judging from Fig. 1 the ice $\mathrm{I}_{\mathrm{h}} \rightarrow$ IX/III transition is quite rapid 


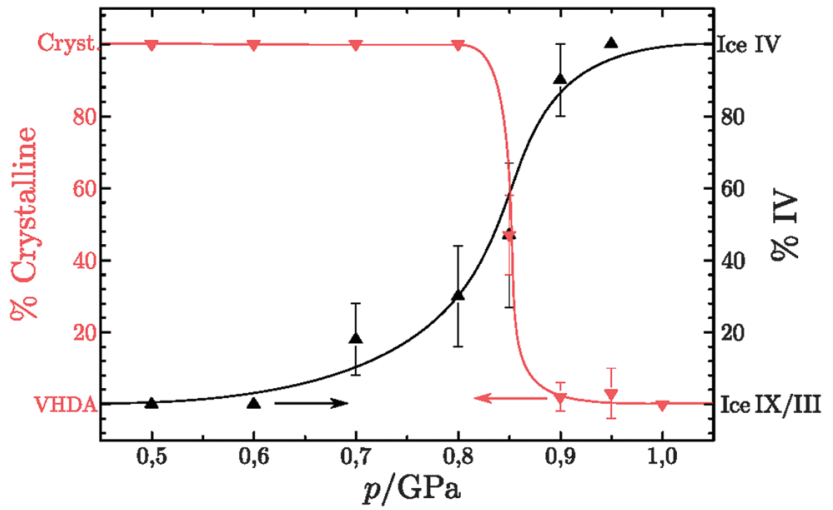

Fig. 4 Mean values of the percentage of crystalline material (left scale, red downward triangles) and percentage of ice IV of the crystalline amount (right scale, black upward triangles) in the samples. No crystallinity implies pure VHDA and no IV indicates that solely ice IX/III constitutes the crystalline amount. The lines are guides to the eye.

and takes place at $\sim 155 \mathrm{~K}$ at $0.50 \mathrm{GPa}$ and $152 \mathrm{~K}$ at $0.60 \mathrm{GPa}$. However, for heating rates of $4 \mathrm{~K} \mathrm{~min}^{-1}$ Salzmann et al. marked $\sim 162 \mathrm{~K}$ rather than $145 \mathrm{~K}$ as the starting temperature for slow crystallisation of ice IV from HDA at $0.81 \mathrm{GPa}^{39}$ It thus remains unclear from the present study done at heating rates of $3 \mathrm{~K} \mathrm{~min}^{-1}$ whether or not ice IV crystallises from incipient VHDA or directly from ice $I_{h}$. The latter option was not reported in literature before, and so it seems more likely that slow amorphisation indeed takes place even at 0.70 and $0.80 \mathrm{GPa}$. Whereas it is not entirely clear whether slow amorphisation plays a role at 0.70 and $0.80 \mathrm{GPa}$, the formation of crystalline and amorphous material compete without a doubt at $\geq 0.85 \mathrm{GPa}$. At pressures $\geq 0.90 \mathrm{GPa}$ formation of amorphous ice, VHDA, dominates, which we call temperature-induced amorphisation (TIA). The competition between temperature-induced polymorphic transformations and TIA is analysed more quantitatively in the following based on the observed changes in volume.

\section{Analysis of the volume curves}

It is possible to relate the shape of the volume curves shown in Fig. 1 to the phase(s) formed after isobaric heating. The two curves labelled 0.50 and $0.60 \mathrm{GPa}$ show a very sharp step, which indicates the polymorphic transition to ice IX/III. The transition temperature of 155 and $152 \mathrm{~K}$, respectively, is in good agreement with the results obtained by Mishima for emulsified ice samples $^{9}$ and with in situ ultrasonic measurements of the isobaric heating of hexagonal ice at $0.65 \mathrm{GPa}^{26}$ The two curves labelled 0.70 and $0.80 \mathrm{GPa}$ show a gentle begin at $\sim 120-150 \mathrm{~K}$ followed by a sharp jump at $150 \mathrm{~K}$ and $149 \mathrm{~K}$, respectively, which is interpreted as slow amorphisation and slow crystallisation to ice IV and subsequent rapid crystallisation to ice IX/III. This finding is consistent with the occurrence of ice IV (see above) and also with Mishima's findings (Region C in ref. 9). The comparison with the ultrasonic study ${ }^{26}$ reveals slight differences. During isobaric heating of hexagonal ice at $0.77 \mathrm{GPa}$ the sequence ice $\mathrm{I}_{\mathrm{h}} \rightarrow \mathrm{HDA} \rightarrow$ ice VI was claimed, ${ }^{26}$ although the latter transition occurred at higher temperatures than reached here. Nevertheless, neither ice
IX/III nor ice IV was mentioned by them, which might be the reason why their density of ice VI was different from the literature density of ice VI. ${ }^{26}$ In our case, ice VI forms upon continued heating from metastable ice IX/III and ice IV rather than from HDA. This actually suggests that Gromnitskaya et al. might not have observed TIA in hexagonal ice, ${ }^{26}$ but similar to us ice $\mathrm{I}_{\mathrm{h}} \rightarrow$ ice IV/III/IX $\rightarrow$ ice VI, maybe with slow amorphisation preceding the transition to ice IV. The next curve at $0.85 \mathrm{GPa}$ shows a lower transition temperature, (Region D in ref. 9), where only amorphisation occurs in emulsified samples upon isothermal compression. The bulk samples studied here transform to both amorphous and crystalline material. Whereas in emulsion crystallisation of the pressure-amorphised ice is efficiently suppressed at $155 \mathrm{~K}$, we here observe crystallisation in temperatureamorphised ice at $155 \mathrm{~K}$. The curves at even higher pressures become progressively less steep and the resulting product is amorphous. Since the crystallisation temperature of amorphous ice increases by $\sim 2 \mathrm{~K} / 0.1 \mathrm{GPa}$ near $1 \mathrm{GPa}^{58}$ crystallisation at $155 \mathrm{~K}$ is suppressed at $\geq 0.9 \mathrm{GPa}$. Ignoring the claims by Gromnitskaya et al. $^{26}$ for the reasons mentioned above this then represent the first observation of temperature-induced amorphisation of hexagonal ice.

For an in-depth analysis the volume curves were fitted by eqn (10) described in the Methods section. An exemplary fit is shown in Fig. 5, and all fit parameters are summarised in Table 2 . The values obtained for the activation energy are depicted in Fig. 6. Most significantly the activation energy drops by about $10 \mathrm{~kJ} \mathrm{~mol}^{-1}$ between 0.80 and $1.00 \mathrm{GPa}$, as a result of amorphisation taking over. At 0.90 and $0.95 \mathrm{GPa}$ again the two-fold behaviour is obvious: either the trend set at lower pressures is followed or the jump to the low activation energy found at $1.00 \mathrm{GPa}$ is observed. This is in agreement with the two sets of diffractograms obtained for these samples (see above). At $\sim 0.75 \mathrm{GPa}$ the two linear fits to the data in Fig. 6 cross, indicating equality of activation energies for amorphisation and polymorphic transformation. At $1.00 \mathrm{GPa}$ the activation energy for amorphisation is about $6 \mathrm{~kJ} \mathrm{~mol}^{-1}$ lower than the activation energy for the polymorphic crystal-tocrystal transformation. The exponent $\beta_{p}^{V_{\mathrm{m}}}$ is used to distinguish

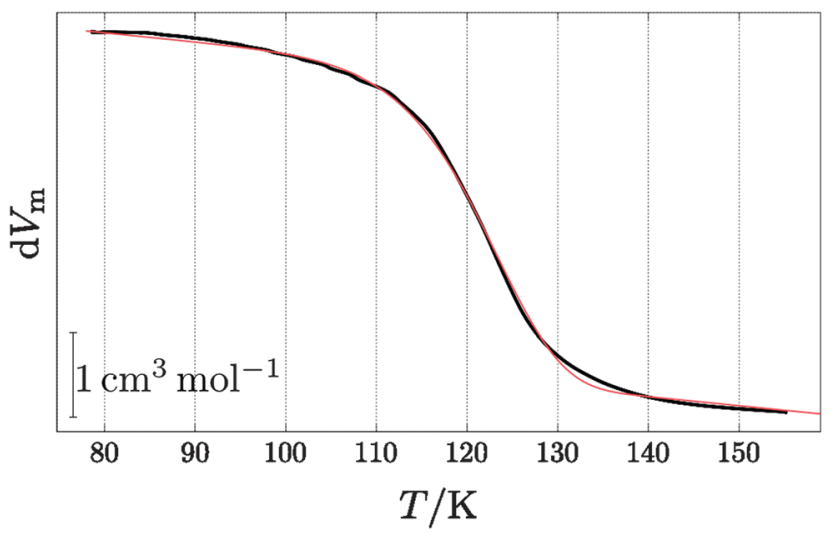

Fig. 5 Example for the fit (red line) of the 0.95 GPa data from Fig. 1 (black line) using eqn (10). 
Table 2 Fit-parameters obtained by fitting the data in Fig. 1 using eqn (10). The starting temperature $T_{0}$ was given and $R^{2}$, RMSE and SSE are statistic measures. Values without errors have been fixed by MATLAB at the bounds

\begin{tabular}{|c|c|c|c|c|c|c|}
\hline$p / \mathrm{GPa}$ & $R^{2}$ & RMSE & SSE & $T_{0} / \mathrm{K}$ & $\Delta_{\mathrm{e}} V_{\mathrm{m}} / \mathrm{cm}^{3} \mathrm{~mol}^{-1}$ & $\tau_{R, \infty} \times 10^{13} / \mathrm{s}$ \\
\hline 0.50 & 0.9977 & 0.0544 & 11.20 & 79.3 & $-3.219 \pm 0.006$ & 1.3 \\
\hline 0.60 & 0.9975 & 0.0589 & 12.29 & 79.8 & $-3.346 \pm 0.007$ & 1.0 \\
\hline 0.70 & 0.9868 & 0.1062 & 37.32 & 77.7 & $-3.283 \pm 0.017$ & 1.0 \\
\hline 0.80 & 0.9902 & 0.1005 & 33.40 & 79.0 & $-3.521 \pm 0.016$ & 1.0 \\
\hline 0.85 & 0.9987 & 0.0419 & 5.80 & 77.6 & $-4.057 \pm 0.013$ & 1.0 \\
\hline 0.90 & 0.9975 & 0.0866 & 24.10 & 78.0 & $-3.500 \pm 0.016$ & 1.0 \\
\hline 0.90 & 0.9988 & 0.0494 & 7.94 & 77.6 & $-3.929 \pm 0.008$ & 1.0 \\
\hline 0.95 & 0.9990 & 0.0498 & 7.94 & 78.6 & $-3.877 \pm 0.009$ & 1.0 \\
\hline 0.95 & 0.9994 & 0.0448 & 6.60 & 78.6 & $-3.543 \pm 0.014$ & 1.0 \\
\hline 1.00 & 0.9996 & 0.0365 & 4.15 & 80.1 & $-3.310 \pm 0.013$ & 1.2 \\
\hline$p / \mathrm{GPa}$ & & $E_{\mathrm{A}} / \mathrm{kJ} \mathrm{mol}^{-1}$ & \multicolumn{3}{|c|}{$\propto_{p}^{V_{\mathrm{m}}} \times 10^{2} / \mathrm{cm}^{3} \mathrm{~mol}^{-1} \mathrm{~K}^{-1}$} & $\beta_{p}^{V_{\mathrm{m}}}$ \\
\hline 0.50 & & $44.7 \pm 2.7$ & \multicolumn{3}{|c|}{$-0.054 \pm 0.005$} & $2.308 \pm 0.050$ \\
\hline 0.60 & & $44.0 \pm 0.9$ & \multicolumn{3}{|c|}{$-0.065 \pm 0.005$} & $3.889 \pm 0.106$ \\
\hline 0.70 & & $42.9 \pm 0.7$ & \multicolumn{3}{|c|}{$-0.425 \pm 0.010$} & $7.700 \pm 0.503$ \\
\hline 0.80 & & $42.7 \pm 0.5$ & \multicolumn{3}{|c|}{$-0.245 \pm 0.010$} & $7.309 \pm 0.275$ \\
\hline 0.85 & & $42.3 \pm 4.1$ & \multicolumn{3}{|c|}{$-0.226 \pm 0.005$} & $1.142 \pm 0.015$ \\
\hline 0.90 & & $37.3 \pm 10.5$ & \multicolumn{3}{|c|}{$-1.000 \pm 0.021$} & $0.800 \pm 0.023$ \\
\hline 0.90 & & $40.3 \pm 5.1$ & \multicolumn{3}{|c|}{$-0.328 \pm 0.008$} & $0.904 \pm 0.012$ \\
\hline 0.95 & & $39.7 \pm 8.1$ & \multicolumn{3}{|c|}{$-0.679 \pm 0.010$} & $0.817 \pm 0.824$ \\
\hline 0.95 & & $35.2 \pm 8.8$ & \multicolumn{3}{|c|}{$-1.245 \pm 0.019$} & $0.547 \pm 0.008$ \\
\hline 1.00 & & $34.0 \pm 7.5$ & \multicolumn{3}{|c|}{$-1.944 \pm 0.020$} & $0.517 \pm 0.527$ \\
\hline
\end{tabular}

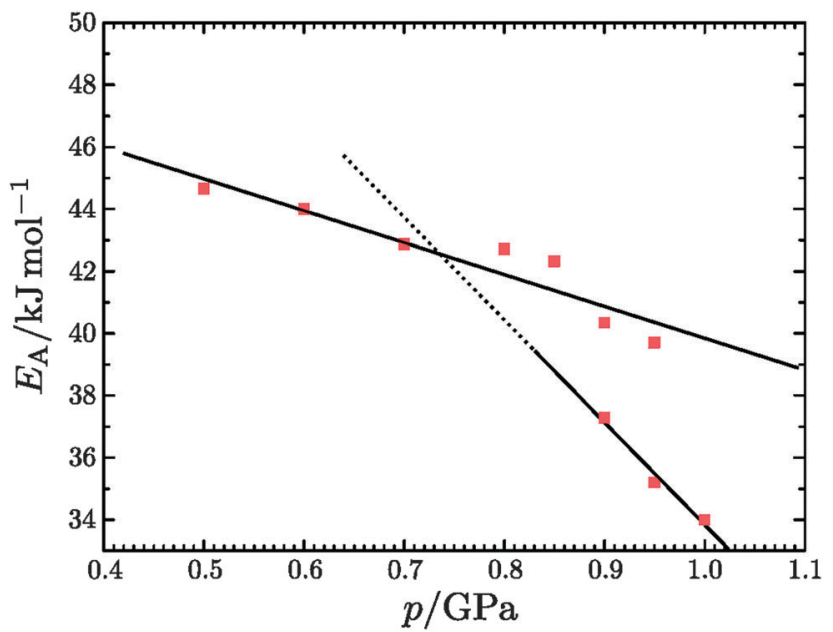

Fig. 6 Activation energies obtained by fitting the volume curves of the isobaric heating of hexagonal ice with eqn (10). The two linear fits correspond to the activation energies for temperature-induced polymorphic transitions (top line) and for temperature-induced amorphisation (bottom line). Upon extrapolation the two lines cross at $\sim 0.75 \mathrm{GPa}$.

first order phase-transitions from other processes. $\beta_{p}^{V_{\mathrm{m}}} \geq 1$ is interpreted to indicate a first order phase-transitions, whereas $\beta_{p}^{V_{\mathrm{m}}}<1$ indicates higher-order phase-transitions. Table 2 lists $\beta_{p}^{V_{\mathrm{m}}}<1$ for the transformations at $0.90,0.95$ and $1.00 \mathrm{GPa}$. This means that TIA is slower than expected for a first-order transition. If one expects the TIA to be thermodynamic melting, one would ad hoc assume a first-order phase transition. However, the transition from hexagonal ice to solid VHDA could also be a higher-order phase transition as it is tantamount to an orderdisorder transition of the oxygen-lattice. By contrast, values of
$\beta_{p}^{V_{\mathrm{m}}}>1$ are listed in Table 2 for the transformations at $<0.90 \mathrm{GPa}$, namely the polymorphic transition $\mathrm{I}_{\mathrm{h}} \rightarrow \mathrm{IX} / \mathrm{III}$ at 0.50 and $0.60 \mathrm{GPa}$ and the crystallisation of the amorphous intermediate at $0.70,0.80$ and $0.85 \mathrm{GPa}$.

Finally we compare our data presented here to PIA experiments to see how those two processes are related, by employing an analysis used previously to compare TIA and PIA for zeolites. ${ }^{15,16}$ For this purpose a characteristic transition time $\tau_{\mathrm{A}}$ was determined from the volume curves and subsequently used to obtain a reduced time axis. Besides the isobaric curves (Fig. 1) we evaluated isothermal PIA curves at 77, 120 and $139 \mathrm{~K}$. For this purpose, one sample with $300 \mu \mathrm{l}$ water and two with $250 \mu \mathrm{l}$ were precompressed up to $1.1 \mathrm{GPa}$ at $77 \mathrm{~K}$ and decompressed. The first sample was thereafter compressed up to $1.7 \mathrm{GPa}$, where PIA occurred. The other samples were compressed to $1.1 \mathrm{GPa}$, one at $120 \mathrm{~K}$ and one at $139 \mathrm{~K}$, where also PIA occurred. All curves (PIA and TIA) were plotted against time and temperature $T_{\mathrm{A}}$ or pressure $p_{\mathrm{A}}$ at half step height were determined. Then the intersection points $T_{\mathrm{e}}$ and $p_{\mathrm{e}}$ of tangents at these points with tangents at the zero step height were determined. From these values and the respective heating- $q$ or compression-rate $\pi$ the characteristic transition time $\tau_{\mathrm{A}}$ was calculated as follows:

$$
\tau_{\mathrm{A}}=\frac{T_{\mathrm{A}}-T_{\mathrm{e}}}{q} \text { or } \tau_{\mathrm{A}}=\frac{p_{\mathrm{A}}-p_{\mathrm{e}}}{\pi}
$$

Fig. 7 shows such a plot against the reduced time $\frac{t}{\tau_{\mathrm{A}}}$, where curves lying on top of each other mark the same process. Three distinct sets of curves can be identified in this plot: one for the polymorphic transformation of hexagonal ice at $\leq 0.80 \mathrm{GPa}$, one for amorphisation of hexagonal ice by TIA at pressures $\geq 0.85 \mathrm{GPa}$, and one for the amorphisation of hexagonal ice by 


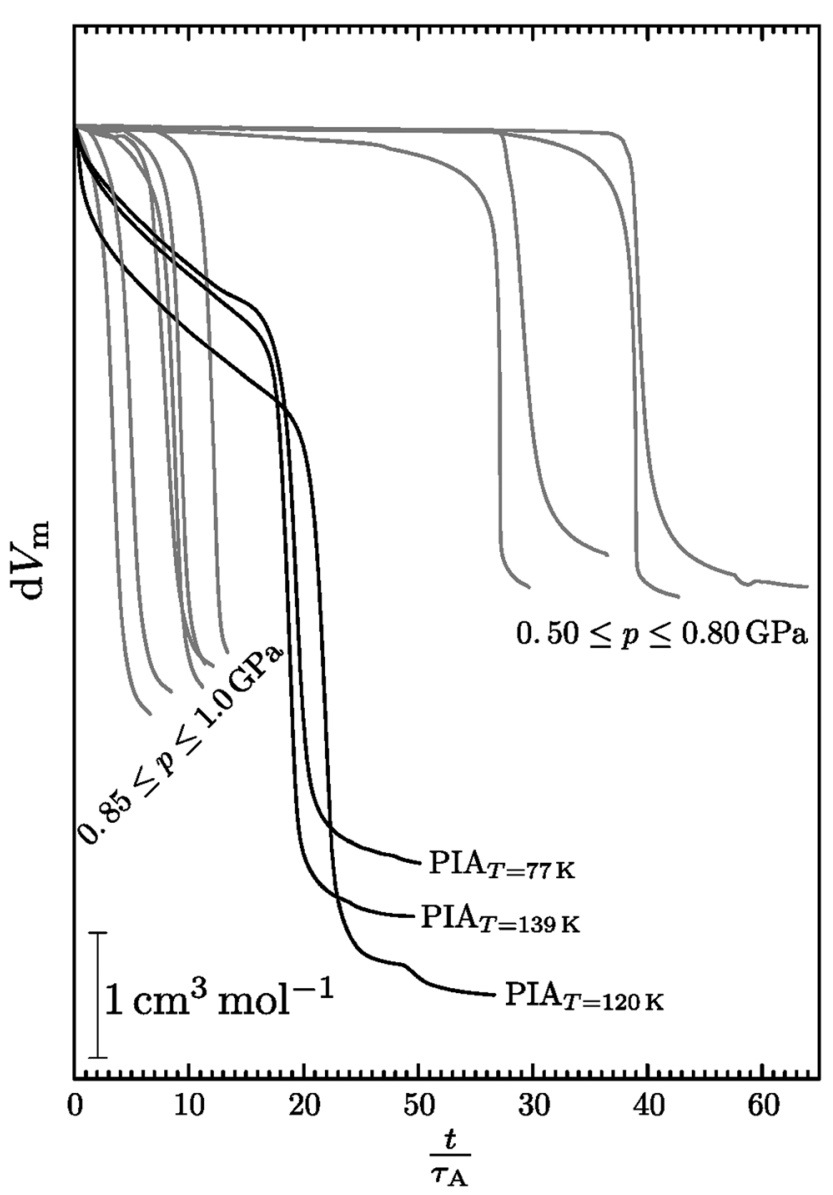

Fig. 7 Change of the molar volume during PIA (black lines) and isobaric transitions of hexagonal ice (grey lines) as a function of reduced time (see eqn (11)).

PIA in the middle. The former set of curves related to the crystal-crystal polymorphic transition stands out most profoundly, whereas the two other blocks marking TIA and PIA are in close proximity. Therefore the two blocks at low reduced times seem to emanate from an - at least - similar process transforming the crystal to an amorphous solid. The TIA block is furthermore more or less ordered in the sense that the highest pressure $(1 \mathrm{GPa})$ shows the lowest reduced time and the lowest pressure $(0.85 \mathrm{GPa})$ the highest reduced time. The curves in between relate to the experiments at 0.95 and $0.90 \mathrm{GPa}$, where the two lower ones show a lower transition temperature (cf. above) and the two higher ones a higher transition temperature. For the transformations to the crystalline polymorphs in contrast no correlation between pressure and reduced time is observed. Interestingly the process of PIA is found to be composed of two processes, a slow volume relaxation in the beginning, which is then followed by a sudden jump in volume. Gromnitskaya et al. named elastic phonon softening to be the common precursor for the solid-state amorphisation induced by pressure. $^{26}$ The initial slow volume decrease in Fig. 7 may be a hallmark of elastic softening. By contrast, TIA shows only the sharp volume change, but not the slow densification in the early stages of amorphisation. That is, temperature-induced amorphisation may take place without appreciable elastic softening prior to the sharp volume change. For this reason, TIA comes closer to represent thermodynamic melting than PIA. ${ }^{59}$ This finding on ice amorphisation is in contrast to the interpretation given by Ortiz et al. ${ }^{3}$ in case of zeolitic material (ZIF-8), who state that TIA does not take place because of the absence of elastic softening. The transition itself takes place at higher pressures and higher temperatures when compared with the conditions at which hexagonal ice and HDA are calculated to be of same chemical potential. ${ }^{37}$ In our interpretation the overpressurization/superheating is a result of a kinetic barrier, e.g., a nucleation barrier, which needs to be overcome at rather low temperature. Such kinetic barriers are hallmarks for first-order transitions. However, we do not extract the order of the transition directly from our data, and so we cannot rule out the possibility of a higher-order transition.

\section{Conclusions}

We have analysed the competition between polymorphic transformations and temperature-induced amorphisation (TIA) for hexagonal ice at $0.50-1.00 \mathrm{GPa}$. Isobaric heating of hexagonal ice between 0.50 and $0.60 \mathrm{GPa}$ leads to a solid-solid transition to ice IX/III. At 0.70 and $0.80 \mathrm{GPa}$ hexagonal ice presumably first slowly transforms to a transient amorphous phase, which slowly crystallises to ice IV, and this slow process is terminated by abrupt transformation from ice $I_{h}$ to IX/III. At higher pressures $(0.85-1.00 \mathrm{GPa})$ the amorphisation finally becomes the dominant process. The change in mechanism to obtain a predominantly amorphous product (VHDA) takes place between 0.85 and $0.90 \mathrm{GPa}$, which is corroborated by the mathematical fits to the observed volume $v s$. temperature curves. The shape of the isobaric volume curves is dominated by polymorphic transformations up to $0.80 \mathrm{GPa}$, whereas it is dominated by amorphisation at higher pressures. This means that the polymorphic transformations are slowing down at high-pressure, whereas amorphisation accelerates. We claim that this represents the first clear observation of TIA of hexagonal ice in literature. The only other case of TIA of hexagonal ice claimed in literature by Gromnitskaya et $a .^{26}$ might have been afflicted with simultaneous formation of ice IV/III/IX.

Experiments at 0.90 and $0.95 \mathrm{GPa}$ show that at these pressures apparently two possibilities exist. Either pure amorphisation or amorphisation with partial crystallisation may take place. This is reflected in either a low or high transition temperature, respectively. This again corroborates that there is severe competition between polymorphic transformation and amorphisation, which is dominated by polymorphic transitions at pressures below, but dominated by amorphisation at pressures above. What parameters exactly determine the course of the experiment at 0.90 and $0.95 \mathrm{GPa}$ remains unclear at this juncture and is beyond our control at the moment. Metastability and an unknown trigger or nucleus inducing amorphisation seem to play an important role in this context. These are hallmarks of first-order phase transitions, and so we suggest 
TIA to be a first-order, discontinuous transition, resembling the melting transition, which requires some overpressurization/ superheating. ${ }^{37}$ We think that a nucleation barrier of the disordered phase in the crystal is at the origin of the kinetic hindrance, but we cannot exclude elastic instabilities. The absence of a pre-cursor process in Fig. 7 for TIA disfavours elastic instabilities, though. This absence of the pre-cursor process is the main difference in mechanism between PIA taking place at low temperatures and TIA taking place at higher temperatures.

For the transitions at 0.50 and $0.60 \mathrm{GPa}$ we rule out an intermediate amorphous state. This is based on the fact that the crystallisation of HDA at $0.51 \mathrm{GPa}$ at a heating rate of $3.5 \mathrm{~K} \mathrm{~min}^{-1}$ is known to lead to mainly ice $\mathrm{V},{ }^{58}$ but the ice $\mathrm{V}$ polymorph was not observed in the present work at similar heating rate. Similarly, ice XII would be expected on crystallizing amorphous ice at $0.50-1.00 \mathrm{GPa},{ }^{41,58,60}$ but also the ice XII polymorph was not observed in this work. According to Salzmann et al. there are two crystallisation channels for HDA: a slow one at lower temperatures and a fast one at higher temperatures. ${ }^{58,60}$ In our experiments here we only observe the first, slow crystallisation channel at lower temperatures. e.g., at $0.71 \mathrm{GPa}$ ice XII crystallises abruptly at $160 \mathrm{~K}$, but we here only heated to a maximum temperature of $155 \mathrm{~K}$. According to literature ice IX/III is not expected as a product of HDA crystallisation at $0.81 \mathrm{GPa},{ }^{39,40,58,60}$ but it appears in this study both at 0.80 and at $0.85 \mathrm{GPa}$. This can be explained by the parallel appearance of the amorphisation and the $\mathrm{I}_{\mathrm{h}} \rightarrow$ IX/III transition, consistent with the change of mechanism in this pressure regime. At higher pressures solely ice IV appears in accord with former studies. $^{58}$

Finally, PIA and TIA seem to be intimately related processes, and so conclusions can be drawn whether PIA should either be regarded as thermodynamic melting or as mechanical collapse. Strässle et al. suggested mechanical collapse to be a temperature independent process. ${ }^{11}$ We here observe TIA at $T>100 \mathrm{~K}$ $\left(T_{\mathrm{e}}^{\mathrm{TIA}}(1.00 \mathrm{GPa}) \geq 103 \mathrm{~K}\right)$. This is higher than the crossover temperature of $80-100 \mathrm{~K}$, above which thermodynamical melting was inferred for PIA in earlier work. ${ }^{11,12}$ Since TIA is obviously a temperature dependent process our study corroborates that PIA at $>100 \mathrm{~K}$ can indeed be considered as thermodynamic melting. By contrast to the volume curves related to PIA, we do not find a slow precursor process attributable to elastic softening from our analysis of volume curves related to TIA. This again suggests that the process of temperatureinduced amorphisation reported here actually reflects thermodynamic melting of ice followed by immediate vitrification, as suggested originally also for the process of pressure-induced amorphisation of hexagonal ice at $77 \mathrm{~K}$ by Mishima. ${ }^{6}$

This process of temperature-induced amorphisation of ice may actually not only be of importance in our understanding of anomalous water properties. In the interior of ice-covered bodies in outer space, TIA may actually be of relevance. Ganymede for instance is well-differentiated into a rocky core and a mantle of relatively pure water-ice, which is about $900 \mathrm{~km}$ thick. At the moon's surface the temperature is close to $80 \mathrm{~K}$ and rises to about $300 \mathrm{~K}$ at the bottom of its icy interior, where the pressure is about $2.5 \mathrm{GPa} .{ }^{61} \mathrm{It}$, thus, seems plausible that in a depth of a few hundred kilometres, there is a competition between amorphisation to VHDA and polymorphic transformation to ice III/IX. Thus, amorphous ice VHDA might exist in the interior of Ganymede and experience phase transformations or show viscous flow, similar to water ice-lava. ${ }^{62}$

\section{Acknowledgements}

We acknowledge funding by grants from the European Research Council (ERC Starting Grant SULIWA) and the Austrian Science Fund FWF (START award Y391 and international project I1392). P.H.H. thanks W. Stadlmayr for helping develop the fitting function.

\section{References}

1 E. G. Ponyatovskii and O. I. Barkalov, Mater. Sci. Rep., 1992, 8, 147-191.

2 R. J. Hemley, A. P. Jephcoat, H. K. Mao, L. C. Ming and M. H. Manghnani, Nature, 1988, 334, 52-54.

3 A. U. Ortiz, A. Boutin, A. H. Fuchs and F.-X. Coudert, J. Phys. Chem. Lett., 2013, 4, 1861-1865.

4 T. Grande, S. Stolen, A. Grzechnik, W. A. Crichton and M. Mezouar, Physica A, 2002, 314, 560-566.

5 S. K. Deb, M. Wilding, M. Somayazulu and P. F. McMillan, Nature, 2001, 414, 528-530.

6 O. Mishima, L. D. Calvert and E. Whalley, Nature, 1984, 310, 393-395.

7 J. S. Tse, J. Chem. Phys., 1992, 96, 5482-5487.

8 J. S. Tse, D. D. Klug, C. A. Tulk, I. Swainson, E. C. Svensson, C. K. Loong, V. Shpakov, V. R. Belosludov, R. V. Belosludov and Y. Kawazoe, Nature, 1999, 400, 647-649.

9 O. Mishima, Nature, 1996, 384, 546-549.

10 T. Strässle, A. M. Saitta, S. Klotz and M. Braden, Phys. Rev. Lett., 2004, 93, 225901.

11 T. Strässle, S. Klotz, G. Hamel, M. M. Koza and H. Schober, Phys. Rev. Lett., 2007, 99, 175501.

12 T. Strässle, A. Caviezel, B. Padmanabhan, V. Y. Pomjakushin and S. Klotz, Phys. Rev. B: Condens. Matter Mater. Phys., 2010, 82, 094103.

13 J. Y. Chen and C. S. Yoo, Proc. Natl. Acad. Sci. U. S. A., 2011, 108, 7685-7688.

14 M. Grimsditch, S. Popova, V. V. Brazhkin and R. N. Voloshin, Phys. Rev. B: Condens. Matter Mater. Phys., 1994, 50, 12984-12986.

15 G. N. Greaves, F. Meneau, A. Sapelkin, L. M. Colyer, I. ap Gwynn, S. Wade and G. Sankar, Nat. Mater., 2003, 2, 622-629.

16 N. Greaves and F. Meneau, J. Phys.: Condens. Matter, 2004, 16, S3459-S3472.

17 S. Ferdov, Angew. Chem., Int. Ed., 2013, 52, 12135-12138.

18 H. N. Kim and S. K. Lee, Am. Mineral., 2014, 99, 1996-2007. 
19 K. W. Chapman, G. J. Halder and P. J. Chupas, J. Am. Chem. Soc., 2009, 131, 17546-17547.

20 T. D. Bennett, D. A. Keen, J. C. Tan, E. R. Barney, A. L. Goodwin and A. K. Cheetham, Angew. Chem., Int. Ed., 2011, 50, 3067-3071.

21 S. Klotz, J. M. Besson, G. Hamel, R. J. Nelmes, J. S. Loveday and W. G. Marshall, Nature, 1999, 398, 681-684.

22 D. D. Klug, Y. P. Handa, J. S. Tse and E. Whalley, J. Chem. Phys., 1989, 90, 2390-2392.

23 C. A. Tulk and D. D. Klug, Phys. Rev. B: Condens. Matter Mater. Phys., 2001, 63, 212201.

24 Y. Yoshimura, H.-k. Mao and R. J. Hemley, Chem. Phys. Lett., 2006, 420, 503-506.

25 A. M. Balagurov, O. I. Barkalov, A. I. Kolesnikov, G. M. Mironova, E. G. Ponyatovskii, V. V. Sinitsyn and V. K. Fedotov, JETP Lett., 1991, 53, 30-34.

26 E. L. Gromnitskaya, O. V. Stal'gorova, V. V. Brazhkin and A. G. Lyapin, Phys. Rev. B: Condens. Matter Mater. Phys., 2001, 64, 094205.

27 T. Loerting, K. Winkel, M. Seidl, M. Bauer, C. Mitterdorfer, P. H. Handle, C. G. Salzmann, E. Mayer, J. L. Finney and D. T. Bowron, Phys. Chem. Chem. Phys., 2011, 13, 8783-8794.

28 N. Giovambattista, K. Amann-Winkel and T. Loerting, Adv. Chem. Phys., 2013, 152, 139-173.

29 T. Loerting, V. Fuentes-Landete, P. H. Handle, M. Seidl, K. Amann-Winkel, C. Gainaru and R. Böhmer, J. Non-Cryst. Solids, 2015, 407, 423-430.

30 H. Engelhardt and B. Kamb, J. Glaciol., 1978, 21, 51-53.

31 H. Engelhardt and B. Kamb, J. Chem. Phys., 1981, 75, 5887-5899.

32 C. Lobban, J. L. Finney and W. F. Kuhs, J. Chem. Phys., 2000, 112, 7169-7180.

33 K. Winkel, W. Schustereder, I. Kohl, C. G. Salzmann, E. Mayer, T. Loerting, in Proc. 11th Intl. Conf. on the Physics and Chemistry of Ice, ed. W. F. Kuhs, RSC, Dorchester, UK, 2007, pp. 641-648.

34 T. Loerting, M. Bauer, I. Kohl, K. Watschinger, K. Winkel and E. Mayer, J. Phys. Chem. B, 2011, 115, 14167-14175.

35 C. T. Moynihan, Rev. Mineral. Geochem., 1995, 32, 1-19.

36 A. D. McNaught, A. Wilkinson, M. Nic, J. Jirat, B. Kosata and A. Jenkins, Compendium of Chemical Terminology (the "Gold Book”), Blackwell Scientific Publications, 1997 (updated 2006).

37 M. A. Floriano, Y. P. Handa, D. D. Klug and E. Whalley, J. Chem. Phys., 1989, 91, 7187-7192.

38 P. G. Debenedetti and F. H. Stillinger, Nature, 2001, 410, 259-267.

39 C. G. Salzmann, T. Loerting, I. Kohl, E. Mayer and A. Hallbrucker, J. Phys. Chem. B, 2002, 106, 5587-5590.

40 C. G. Salzmann, I. Kohl, T. Loerting, E. Mayer and A. Hallbrucker, Can. J. Phys., 2003, 81, 25-32.

41 S. Klotz, G. Hamel, J. S. Loveday, R. J. Nelmes and M. Guthrie, Z. Kristallogr., 2003, 218, 117-122.

42 B. Kamb and A. Prakash, Acta Crystallogr., Sect. B: Struct. Crystallogr. Cryst. Chem., 1968, 24, 1317-1327.
43 S. J. LaPlaca, W. C. Hamilton, B. Kamb and A. Prakash, J. Chem. Phys., 1973, 58, 567-580.

44 K. Echelmeyer and B. Kamb, Geophys. Res. Lett., 1986, 13, 693-696.

45 M. Bauer, M. S. Elsaesser, K. Winkel, E. Mayer and T. Loerting, Phys. Rev. B: Condens. Matter Mater. Phys., 2008, 77, 220105.

46 M. Bauer, K. Winkel, D. M. Toebbens, E. Mayer and T. Loerting, J. Chem. Phys., 2009, 131, 224514.

47 J. Urquidi, C. J. Benmore, P. A. Egelstaff, M. Guthrie, S. E. McLain, C. A. Tulk, D. D. Klug and J. F. C. Turner, Mol. Phys., 2004, 102, 2007-2014.

48 T. Loerting, C. Salzmann, I. Kohl, E. Mayer and A. Hallbrucker, Phys. Chem. Chem. Phys., 2001, 3, 5355-5357.

49 J. E. Bertie, L. D. Calvert and E. Whalley, J. Chem. Phys., 1963, 38, 840-846.

50 Y. P. Handa, D. D. Klug and E. Whalley, Can. J. Chem., 1988, 66, 919-924.

51 C. G. Salzmann, E. Mayer and A. Hallbrucker, Phys. Chem. Chem. Phys., 2004, 6, 1269-1276.

52 K. Winkel, Study of Amorphous-Amorphous Transitions in Water, Verlag Dr. Hut, Munich, 2011.

53 Y. P. Handa, O. Mishima and E. Whalley, J. Chem. Phys., 1986, 84, 2766-2770.

54 I. Kohl, E. Mayer and A. Hallbrucker, Phys. Chem. Chem. Phys., 2000, 2, 1579-1586.

55 I. Kohl, Amorphes festes Wasser hoher Dichte und sein Phasenübergang zu Eis XII, PhD thesis, University of Innsbruck, 2001.

56 K. Winkel, D. T. Bowron, T. Loerting, E. Mayer and J. L. Finney, J. Chem. Phys., 2009, 130, 204502.

57 M. S. Elsaesser, K. Winkel, E. Mayer and T. Loerting, Phys. Chem. Chem. Phys., 2010, 12, 708-712.

58 C. G. Salzmann, E. Mayer and A. Hallbrucker, Phys. Chem. Chem. Phys., 2004, 6, 5156-5165.

59 G. P. Johari and O. Andersson, Soft Matter under Exogenic Impacts, NATO Science Series II: Mathematics, Physics and Chemistry, 2007, vol. 242, pp. 35-74.

60 C. G. Salzmann, Relaxation und Kristallisation von hochdichtem amorphen Eis unter Druck und Charakterisierung der hergestellten metastabilen Eismodifikationen IV und XII, PhD thesis, University of Innsbruck, 2003.

61 J. Leliwa-Kopystynski, Adv. Space Res., 1995, 15, 69-78.

62 P. M. Schenk, W. B. McKinnon, D. Gwynn and J. M. Moore, Nature, 2001, 410, 57-60.

63 C. Lobban, J. L. Finney and W. F. Kuhs, Nature, 1998, 391, 268-270.

64 V. F. Petrenko and R. W. Whitworth, Physics of Ice, Oxford University Press, Oxford, 1999.

65 J. D. Londono, W. F. Kuhs and J. L. Finney, J. Chem. Phys., 1993, 98, 4878-4888. 